\title{
Pattern of Childhood Tuberculosis in the Outpatient Department of a Tertiary Level Hospital in Dhaka City
}

\author{
Md. Mozammel Haque ${ }^{1, ~ *, ~ M d . ~ A b d u l l a h-A l-M a r u f ~}{ }^{2}$, Abdullah Al Baki ${ }^{1}$, A. Z. M. Motiur Rahman ${ }^{1}$, \\ Md. Arif Rabbany ${ }^{3}$, Dhiman Chowdhury ${ }^{4}$, Muhammad Jabed Bin Amin Chowdhury ${ }^{4}$, \\ Muhammad Ismail Hasan ${ }^{5}$, Mohammad Morshad Alam ${ }^{5}$, Jugindra Singha ${ }^{6}$, \\ Md. Shohidul Islam Khan ${ }^{6}$, Md. Humayan Kabir ${ }^{6}$, Mohammed Golam Mowla ${ }^{7}$, \\ Kamrunnaher Shultana ${ }^{8}$
}

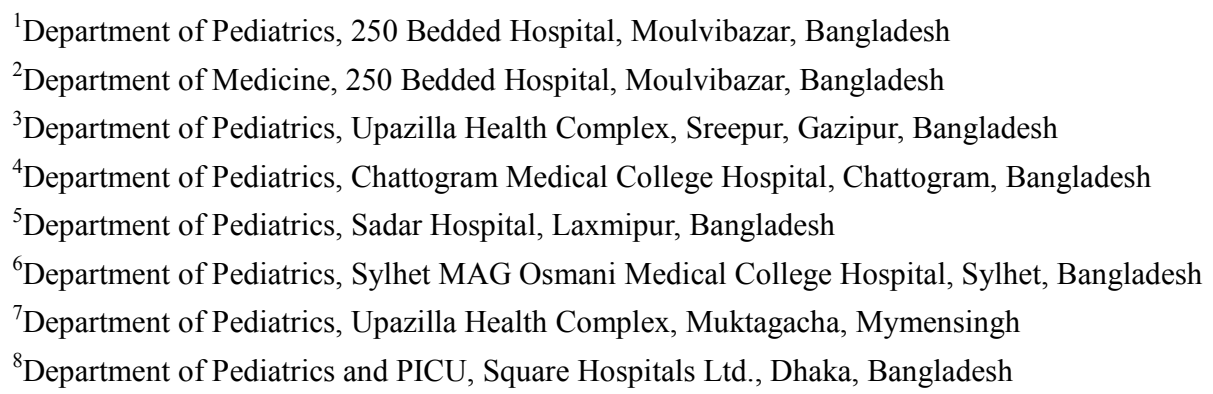

Email address:

mmhaque16rmc@yahoo.com (Md. M. Haque),drmaruf58@gmail.com (Md. Abdullah-Al-Maruf), abdullahalbaki09@gmail.com (A.Al Baki),azmmotiur.rahman@gmail.com (A. Z. M. M. Rahman), arifdrmmc@gmail.com (Md. A. Rabbany), dhimanchow@gmail.com (D. Chowdhury), jabedbinamin@yahoo.com (M. J. B. A. Chowdhury), dr.ismai198@gmail.com (M. I. Hasan),dr.morshadalam36@yahoo.com (M. M. Alam), sjugindra@gmail.com (J. Singha), drsikhan49@gmail.com (Md. S. I. Khan), humayan.somc@gmail.com (Md. H. Kabir), dr.mdgmowla@gmail.com (M. G. Mowla), dina_bd2010@yahoo.com (K. Shultana)

${ }^{*}$ Corresponding author

\section{To cite this article:}

Md. Mozammel Haque, Md. Abdullah-Al-Maruf, Abdullah Al Baki, A. Z. M. Motiur Rahman, Md. Arif Rabbany, Dhiman Chowdhury, Muhammad Jabed Bin Amin Chowdhury, Muhammad Ismail Hasan, Mohammad Morshad Alam, Jugindra Singha, Kamrunnaher Shultana. Pattern of Childhood Tuberculosis in the Outpatient Department of a Tertiary Level Hospital in Dhaka City. International Journal of Infectious Diseases and Therapy. Vol. 5, No. 2, 2020, pp. 23-28. doi: 10.11648/j.ijidt.20200502.11

Received: March 22, 2020; Accepted: April 9, 2020; Published: May 15, 2020

\begin{abstract}
Introduction: Tuberculosis (TB) in children is increasingly becoming an important cause of global child morbidity and mortality. Objective: The objective of this study was to evaluate the clinical spectrum of TB in children under the age of 15 years and document any changes that occur over time. Materials \& Methods: This observational study was conducted in the pediatric outpatient department (OPD) of 250 Bedded TB Hospital, Shyamoli, Dhaka, from October'2016 to January'2017. A total 71 children of both sex up to 15 years of age, who were diagnosed as having TB and attended the pediatric OPD of TB hospital during the four months study period were enrolled. The data was analyzed on the basis of patient's age, gender, socioeconomic status, mode of presentation, BCG vaccination status, history of contact with smear positive TB patient, clinical findings, investigations and associated co-morbidities. Results: This study revealed that among the 71 cases of TB, (72\%) had extra-pulmonary TB (EPTB) and (28\%) had pulmonary TB (PTB), the commonest age group was 6 to 15 years with male preponderance (51\%). Pulmonary TB was diagnosed mostly clinically (60\%) followed by positive sputum smear result (20\%), gastric aspirate for acid-fast bacilli AFB (5\%) and sputum for Gene Xpert (5\%). Distribution of extra-pulmonary TB (EPTB) according to the organ involvement was TB lymphadenitis (49\%), osteoarticular TB (19.6\%) and abdominal TB (5.9\%). Cervical lymphadenopathy was the commonest presentation (76\%) among the EPTB cases. Tuberculin skin test (TST) was positive in $(69 \%)$ cases. Among the total cases $(90 \%)$ children had TB alone whereas $(10 \%)$ had other co-morbid disease along with TB. Conclusion: Extra-pulmonary TB (EPTB) was more prevalent among the childhood TB cases in a tertiary level set up
\end{abstract}


where cervical TB lymphadenitis was the commonest.

Keywords: Childhood TB, Pulmonary TB, Extra-pulmonary TB

\section{Introduction}

Tuberculosis (TB) caused by the Mycobacterium tuberculosis remains as an infection of tremendous clinical and public health importance worldwide. Despite the accelerated efforts to control TB for decades, it remains the seventh leading cause of death globally [1]. World Health Organization (WHO) estimated that over 1.3 million cases of TB and 450000 associated deaths occur annually in children [2] which represent about (6\%) of the global TB burden [3]. WHO in 2007 showed that smear-positive TB in children aged 14 years accounted for $(0.6 \%-3.6 \%)$ of all reported cases and the majority reside in Africa and Southeast Asia [4]. This finding suggests that children in developing countries will emerge as a high risk group eventually. In 2013, WHO estimated that up to 80,000 HIV children die from TB [5]. A study estimated the incidence of TB infection and disease among children in 22 high burden countries which reveals that 53 million has latent infection, 7.6 million $(14.3 \%)$ has active infection with TB and 650,000 (1.2\%) developed the disease finally [5]. The annual risk of TB infection in children in developing countries is (2\%-5\%). About (8\%-20\%) of deaths due to TB occur in children [7, 8]. TB in children is increasingly becoming an important cause of global child morbidity and mortality.

In Bangladesh, child TB represents $(10 \%)$ of the total TB cases and remains a major cause of morbidity and mortality [1] and the burden of TB patients is the sixth of its world burden [9]. TB in children is a direct consequence of adult $\mathrm{TB}$ and is a good marker of current transmission in the community. The two main factors detecting the risk of progression to disease are patient's age and immune status [10-15]. Although the pulmonary TB is the most common presentation, extra-pulmonary $\mathrm{TB}$ accounts for up to one third of all cases of TB [7, 16-18]. Tuberculosis involves organ other than the lungs such as serous membrane, lymphnodes, abdomen, genitourinary tract, skin, joints, bones, meninges which are included as extra-pulmonary TB. Tuberculosis in children is mostly related to primary infection and it presents with various forms of relatively less aggressive primary TB [7, 16-18]. However contrary to the common notion, aggressive forms of pulmonary TB akin to adult forms are increasingly seen in pediatric clinical practice especially in adolescents [7, 16-18].

The most common form of childhood TB, the classical primary complex consists of a focal parenchymal lesion typically seen in lungs, at mid-lower zones with enlarged draining hilar/paratracheal node. Along with pulmonary manifestations, $(25 \%$ to $35 \%)$ children have an extrapulmonary presentation $[19,20]$. The most common extrapulmonary form of TB is lymphatic which accounts for about two thirds of all cases of EPTB. The second most common form is meningeal form arising in (13\%) of children with TB $[19,20]$.

The clinical and physical manifestations of disease tend to be different by the age of onset of disease. Neonates are at higher risk of progression of infection to disease, with higher rate of miliary TB and meningeal involvement [20]. Preschool children and adolescents are more likely to have significant signs or symptoms, whereas school-age children often have clinically silent disease. Half of young children with radio-graphically moderate to severe pulmonary $\mathrm{TB}$ don't have any symptoms or physical findings and, mainly, are detected by contact tracing of an adult with pulmonary TB [11-15]. Infants also, are more likely to experience clinical manifestations of TB, may be due to small airway diameters. Non-productive cough and mild dyspnea are the most common symptoms in this age group. Systemic complaints such as anorexia, fever, and night sweats occur less commonly. Some infants have difficulty in gaining weight and growing up. Some infants and young children with bronchial obstruction show localized wheezing or decreased breath sounds that may be accompanied by tachypnea or respiratory distress [11-15]. Children between 5 to 10 years are less likely to develop disease than other age groups, and adolescent patients can present with progressive primary pulmonary TB or cavitary disease $[11-15,19,20]$. The diagnosis of childhood Tuberculosis still remains a major challenge, as it is complicated by the absence of a practical "gold standard" [21, 22]. Bacteriologic confirmation, the accepted gold standard, is of limited use in children because of the paucibacillary nature of their disease and poor bacteriologic yields. Sputum smear microscopy, often the only diagnostic test available in endemic areas, is positive in less than $(10 \%$ to $15 \%)$ of children with probable TB [23] and mycobacterial culture detects the bacilli in $(30 \%-40 \%)$ cases $[22,24]$. Best specimen for diagnosis of pulmonary $\mathrm{TB}$ in a child is the early morning gastric lavage $[25,26]$. Gastric aspirates detect Mycobacterium tuberculosis in less than $(50 \%)$ of cases and a negative culture never excludes the diagnosis of PTB [27-30]. In the absence of bacteriological confirmation, the diagnosis of childhood TB in endemic countries is based on close contact with an infectious patient, presence of suggestive clinical signs and symptoms, a positive Tuberculin skin test (TST), and/or abnormalities on x-ray [31-34]. Though the chest radiograph is a valuable diagnostic tool, its findings may be normal for a significant proportion of children with confirmed pulmonary TB. Now a days, PCR is being used for species identification, molecular epidemiology and rapid detection of drug resistance $[35,36]$.

Over the last few years, interest of WHO in childhood TB has increased dramatically. For the first time ever, in 2012, WHO included an estimate for childhood TB in their annual 
report [37] and in 2012, the focus of World TB Day was children [37]. The global TB control strategy has focused predominantly on smear-positive cases and, therefore, not on childhood $\mathrm{TB}$ as it is usually paucibacillary and smear negative [38]. In addition, childhood TB remains neglected for various reasons, mainly the difficulty in diagnosing pulmonary $\mathrm{TB}$, the lack of scientific studies on childhood $\mathrm{TB}$, the largely unknown outcomes of children with TB and the belief that childhood TB is not important for TB control $[38,39]$. Further research, understanding and prevention of TB among children are urgently needed. The overall objective of this study was to evaluate the clinical spectrum of TB in children in a tertiary care hospital under the age of 15 years.

\section{Materials \& Methods}

This study was conducted in the pediatric outpatient department (OPD) of 250 Bedded TB Hospital, Shyamoli, Dhaka, from October'2016 to January'2017. This tertiary level health care facility receives referred TB patients from the other primary, secondary or tertiary hospitals all around the country and also from the chamber of private practitioners. A total 71 children of both sex, age 0 to 15 years were enrolled in this survey. The children who were already diagnosed as TB patient in this hospital or elsewhere, already on anti-TB drugs or going to be introduced anti-TB therapy who came to the OPD of 250 Bedded TB Hospital during the four months period were sequentially enrolled. This was an observational study conducted for a prespecified four months period and hence the statistical methods for sample size determination and randomization was not applied. For the confirmation of TB in children, case specific diagnostic modalities were used by the primary attending physician like clinical response to anti-TB therapy (who were not responded to other antibiotics previously), Tuberculin skin test (TST), smear test (sputum/gastric lavage), chest x-ray, fine needle aspiration cytology (FNAC) or biopsy etc. So, it was not considered mandatory by the primary physician doing chest x-ray or TST in all children. All the lymph node TB cases (except the mediastinal nodes) were diagnosed either by FNAC or biopsy. The data was analyzed on the basis of patient's age, gender, socioeconomic status, mode of presentation, BCG vaccination status, history of contact with smear positive TB patient, clinical findings, investigations and associated co-morbidities. Written informed consent was taken from the patients and ethical clearance was taken from the appropriate authority.

\section{Result}

Table 1 showed that, among the total 71 cases of childhood $\mathrm{TB}$, the common age group was $6-15$ years $(68 \%)$ with male preponderance $(51 \%)$. School going and urban children were affected more, $(61 \%) \&(79 \%)$ respectively. Prevalence of child TB was more common (42\%) in upper middle income group (9000-17999 taka per month) and children of drivers
(23\%). Eighty three percent studied children had contact with smear positive PTB patient. Ninety six percent of the enrolled children were BCG vaccinated.

Table 1. Socio-demographic characteristics of the studied children $(n=71)$ Data are presented as number (\%).

\begin{tabular}{|c|c|c|}
\hline Patient profile & Variables & Number $(\%)$ \\
\hline \multirow{2}{*}{ Age } & $0-5$ years & $23(32 \%)$ \\
\hline & $6-15$ years & $48(68 \%)$ \\
\hline \multirow{2}{*}{ Sex } & Male & $36(51 \%)$ \\
\hline & Female & $35(49 \%)$ \\
\hline \multirow{3}{*}{ Education } & No schooling $^{\infty}$ & $24(33 \%)$ \\
\hline & School student & $43(61 \%)$ \\
\hline & Madrasa student & $4(6 \%)$ \\
\hline \multirow{2}{*}{ Living area } & Rural $^{\curvearrowleft}$ & $16(21 \%)$ \\
\hline & Urban $^{*}$ & $55(79 \%)$ \\
\hline \multirow{4}{*}{ Socio economic status } & Upper & $23(32 \%)$ \\
\hline & Upper middle $^{\Omega}$ & $30(42 \%)$ \\
\hline & Lower middle $^{\mathcal{O}}$ & $10(14 \%)$ \\
\hline & Lower & $8(12 \%)$ \\
\hline \multirow{5}{*}{$\begin{array}{l}\text { Frequency of parent's } \\
\text { profession }\end{array}$} & Day laborers & $6(8 \%)$ \\
\hline & Driver & $16(23 \%)$ \\
\hline & Small traders & $9(13 \%)$ \\
\hline & Garment workers & $3(4 \%)$ \\
\hline & Others & $37(52 \%)$ \\
\hline \multirow{2}{*}{ Contact with TB patient } & Present & $12(17 \%)$ \\
\hline & Absent & $59(83 \%)$ \\
\hline \multirow{2}{*}{ BCG status } & Vaccinated & $68(96 \%)$ \\
\hline & Not vaccinated & $3(4 \%)$ \\
\hline
\end{tabular}

${ }^{\infty}$ Either minor or did not go to school for some other reasons.

"Living in village or upazilla (sub district) level. ${ }^{¥}$ Living in district and/or metropolitan city.

Monthly income 18,000 taka. ${ }^{\Omega}$ Monthly income 9000-17999 taka. ${ }^{\circ}$ Monthly income 6500-8999 taka. "Monthly income $<6500$ taka.

(Source: Kuppuswamy classification of socioeconomic status-January 2015).

Table 2 shows the pattern of TB, where pulmonary TB was $(28 \%)$ and extra-pulmonary TB was (72\%). Among the pulmonary cases smear negative and among the extrapulmonary cases TB lymphadenitis constituted the highest percentage, $(60 \%) \&(49 \%)$ respectively.

Table 2. Distribution of pattern of TB among studied children ( $n=71)$ Data are presented as number (\%).

\begin{tabular}{lll}
\hline Pattern of TB No (\%) & Sub category & Number (\%) \\
\hline \multirow{2}{*}{ Pulmonary TB 20 (28\%) } & Smear negative & $12(60 \%)$ \\
& Smear positive & $08(40 \%)$ \\
& TB lymphadenitis & $25(49 \%)$ \\
& Osteoarticular TB & $10(19.6 \%)$ \\
& Abdominal TB & $03(5.9 \%)$ \\
Extra-pulmonary TB 51 & Localized TB abscess & $03(5.9 \%)$ \\
$(72 \%)$ & Pleural effusion & $03(5.9 \%)$ \\
& TB meningitis & $02(4 \%)$ \\
& TB osteomyelitis & $02(4 \%)$ \\
& Brain abscess & $01(2 \%)$ \\
& Pericardial TB & $01(2 \%)$ \\
& Disseminated TB & $01(2 \%)$ \\
\hline
\end{tabular}

In Table 3, involvement of different groups of lymph node is shown where the most common group of lymph node was 
cervical $(76 \%)$ followed by inguinal $(12 \%)$, mediastinal $(8 \%)$ and axillary (4\%).

Table 3. Distribution of TB lymphadenitis $(n=25)$ Data are presented as number (\%).

\begin{tabular}{ll}
\hline Site of Involvement & Number (\%) \\
\hline Cervical & $19(76 \%)$ \\
Inguinal & $03(12 \%)$ \\
Mediastinal & $02(8 \%)$ \\
Axillary & $01(4 \%)$ \\
\hline
\end{tabular}

Clinical presentation of pulmonary and extra-pulmonary TB in children is shown in Tables $4 \& 5$ respectively. In case of pulmonary $\mathrm{TB}$, most of the children presented with fever $(80 \%)$, cough $(75 \%)$ and anorexia $(40 \%)$. In case of EPTB, most of the children (52\%) presented with systemic manifestation than only lymph node presentation.

Table 4. Clinical presentation of pulmonary TB among the studied children $(n=20)$ Data are presented as number (\%)

\begin{tabular}{ll}
\hline Presentation & Number (\%) \\
\hline Fever & $16(80 \%)$ \\
Cough & $15(75 \%)$ \\
Anorexia & $08(40 \%)$ \\
Chest Pain & $07(35 \%)$ \\
Dyspnea & $06(30 \%)$ \\
Weight loss & $05(25 \%)$ \\
Not gaining weight & $02(10 \%)$ \\
\hline
\end{tabular}

Table 5. Clinical presentation of TB lymphadenitis among the studied children (n=25) Data are presented as number (\%).

\begin{tabular}{ll}
\hline Presentation & Number (\%) \\
\hline Systemic presentation & $13(52 \%)$ \\
Local (only lymph node) presentation & $12(48 \%)$ \\
\hline
\end{tabular}

Table 6 shows the number of children having contact with smear positive pulmonary TB cases which was (14\%) of the total $(\mathrm{n}=71)$. TST was not performed as a diagnostic tool by the primary attending physician in 42 patients, so, $n=29$. In this study TST $\geq 10 \mathrm{~mm}$ was considered positive which was $(69 \%)$ [Table 7].

Table 6. Distribution of studied children according to history of contact with smear positive case $(n=71)$ Data are presented as number (\%)

\begin{tabular}{ll}
\hline Contact with smear positive case & Number (\%) \\
\hline Absent & $61(86 \%)$ \\
Present & $10(14 \%)$ \\
\hline
\end{tabular}

Table 7. Status of Tuberculin skin test (TST) among studied children ( $n=29)$ Data are presented as number (\%).

\begin{tabular}{ll}
\hline Diameter of induration & Number (\%) \\
\hline$<10 \mathrm{~mm}$ & $09(31 \%)$ \\
$\geq 10 \mathrm{~mm}$ & $20(69 \%)$ \\
\hline
\end{tabular}

\section{Discussion}

According to WHO, TB is a worldwide pandemic [40]. In 2008, WHO ranked Bangladesh sixth among the world's 22 high TB burden countries [41]. The incidence of both pulmonary and extra-pulmonary TB is expected to rise [42]. In this study, EPTB constituted $(72 \%)$ of all cases of TB, while about ( $15 \%$ to $20 \%)$ was reported by Fanning [43, 44] and $(10 \%)$ by Haegi $[43,44]$. Study done by Charlett, et al. [45], in the United Kingdom, showed (15\%) British children presented with extra-pulmonary TB whereas in Bangladeshi, Pakistani or Indian ethnic, it was (50\%) [45]. According to our national child TB guideline EPTB accounts for about (30\%) of TB in children [46], as seen in high burden country. Although this study result did not represent the national incidence of child TB, this figure indicated that there was a gap between the National Tuberculosis Control Program (NTP) reported child TB and actual disease burden in the community [46].

In this study, the majority of EPTB cases presented with TB lymphadenitis (49\%) and the commonest lymph node involved was the cervical group (76\%). A study by Shafiullah [47] showed the lymph nodes to be the most common site of EPTB as observed in $(66 \%)$ of studied cases which was consistent with this study result. In a study in Hong Kong [17], the most common site of EPTB was the pleura, followed by the lymph nodes. Another study in Holland [48] showed that the most common sites of EPTB were both pleura and lymph node (17\% for each).

In this study the commonest group of lymph node involved in TB lymphadenitis was cervical (76\%) followed by inguinal $(12 \%)$ and mediatsinal $(8 \%)$. A study by Hatwal D [49] showed that cervical lymphadenopathy was the commonest presentation followed by axillary and inguinal which was almost similar to our study.

A study by Napoleon [50] showed that fever, cough, weight loss, expectoration and hemoptysis were the commonest symptoms among the PTB cases which was consistent with this study where the most of the patient with PTB presented with fever $(80 \%)$, cough $(75 \%)$, anorexia (40\%) and weight loss (35\%). Another study by Hatwal D [51] showed that all of the EPTB cases presented with fever, anorexia, weight loss, malaise and the result was also comparable to this study.

Dhara, et al. [51] in his study showed that history of contact with smear positive TB patient was $(28 \%)$ which was $(17 \%)$ in this study. This can be explained by the lack of knowledge or awareness among people about TB, its clinical symptoms and the need for consultation with physician for proper diagnosis in our country which hinders the screening and identification of smear positive cases. In the same study done by Hatwal D [49] showed that positive TST was present in $(70.85 \%)$ of the study cases which was also similar to our study result (69\%).

\section{Conclusion and Recommendation}

From the present study it can be concluded that extrapulmonary TB (EPTB) was more prevalent among childhood Tuberculosis in a tertiary level set up where cervical TB lymphadenitis was the commonest. This short duration study 
involved a small number of patients, so, further large scale multi-center study is recommended to delineate the original TB scenario in the country.

\section{References}

[1] Hirozi E. Studies on the Cause of Death of the Registered TB Patients. Kurume Med J 1970; 17 (2): 55-60.

[2] Raviglione M, Kochi A. Global Epidemiology of Tuberculosis. Morbidity and Mortality ofa Worldwide Epidemic. JAMA 1995; 273 (3): 220-226.

[3] Shanmuganathan R, Shanmuganathan ID. Clinical Manifestation and Risk Factors of Tuberculosis Infection in Malaysia: Case Study of a Community Clinic. Glob J Health Sci 2015; 7 (4): 110-120.

[4] Au-Yeung C, Kanters S, Ding E, Glaziou P, Anema A, Cooper CL, et al. Tuberculosis Mortality in HIV-Infected Individuals: A Cross-national Systematic Assessment. Clinical Epidemiology 2011; 3: 21-29.

[5] Rein MJ, Peter JD. The Global Burden of Latent TB Infection: A Re-estimation Using Mathemetical Modeling. PloS Med 2016; 13 (10): e100 2152.

[6] Dodd P, Gardiner E, Coghlan R, Seddon J. Burden of Childhood Tuberculosis in 22 High-Burden Countries: A Mathematical Modeling Study. The Lancet Global Health 2014; 2 (8): 453-459.

[7] Rieder H. Annual Risk of Infection with Mycobacterium Tuberculosis. ERJ 2005; 25: 181-185.

[8] Walls T, Shingadia D. Global Epidemiology of Pediatric Tuberculosis. J Infect 2004; 48 (1): 13-22.

[9] Zafar U, Naser A, Huque R, Begum V. Public-Private Partnership for TB Control in Bangladesh: Role of Private Medical Practitioners in the Management of TB Patients. World Medical \& Health Policy 2010: 2 (1): 210-227.

[10] Perez-Velez CM, Marais BJ. Tuberculosisin Children. NEJM 2012; 367 (4): 348-361.

[11] Nejat S, Buxbaum C, Eriksson M, Pergert M, Bennet R. Pediatric Tuberculosis in Stockholm. PIDJ 2012; 31 (3): 224-227.

[12] Endorf F, Garrison M, Klein M, Richardson A, Rivara F. Characteristics, Therapies and Outcome of Children With Necrotizing Soft Tissue Infections. PIDJ 2012; 31 (3): 221223.

[13] Marais B, Gupta A, Starke J, El Sony A. Tuberculosis in Women and Children. The Lancet 2010; 375 (9731): 20572059.

[14] Soumya S, Banu R. Pediatric Tuberculosis: Global Overview and Challenges. ClinInfec Dis 2010: 50 (3): 184-194.

[15] Hoskyns W. Pediatric Tuberculosis. Postgrad Med J 2003; 79 (931): 272-278.

[16] Topley JM, Maher D, Mbewe LN. Transmission of Tuberculosis to Contacts of Sputum Positive Adults in Malawi. Arch Dis Child 1996; 74 (2): 140-143.

[17] Noertjojo K, Tam CM, Chan SL, Chan-Yeung MM. Extra- pulmonary and Pulmonary Tuberculosis in Hong Kong. Int $\mathbf{J}$ Tuberc Lung Dis 2002; 6 (10): 879-886.

[18] Musellim B, Erturan S, Sonmez DE, Ongen G. Comparison of Extra-Pulmonary and Pulmonary Tuberculosis Cases: Factors Influencing the Site of Reactivation. Int J Tuberc Lung Dis 2005; 9: 1220-1223.

[19] Sankalp Y, Gautam R. Primary Extra-Pulmonary Multidrug Resistant Tuberculosis of the Sternum without HIV Infection. JCDR 2017; 11 (1): 1-3.

[20] Starke JR. Pediatric Tuberculosis: Time for a New Approach. Tuberculosis (Edinb) 2003; 83: 208-12.

[21] Starke JR. Childhood Tuberculosis: A Diagnostic Dilemma. Chest 1993; 104: 329-333.

[22] Eamranond P, Jaramillo E. Tuberculosis in Children: Reassessing the Need for Improved Diagnosis in Global Control Strategies. IntJTuberc Lung Dis 2000; 5: 594-603.

[23] Zar HJ, Hanslo D, Apolles P, Swingler G, Hussey G. Induced Sputum Versus Gastric Lavage for Microbiological Confirmation of Pulmonary Tuberculosis in Infants and Young Children: A Prospective Study. Lancet2005; 365: 130-134.

[24] Cruz AT, Starke JR. Clinical Manifestations of TB in Children. PediatrRespir Rev 2007; 8: 107-117.

[25] Graham SM, Ahmed T, Amanullah F, Browning R, Cardenas V, Casenghi M, et al. Evaluation of Tuberculosis Diagnostics in Children: 1. Proposed Clinical Case Definitions for Classification of Intrathoracic Tuberculosis Disease. Consensus from an Expert Panel. J Infect Dis 2012; 205 (2): 199-208.

[26] Zar HJ, Connell TG, Nicol M. Diagnosis of Pulmonary Tuberculosis in Children: New Advances. Expert Rev Anti Infect Ther 2010; 8 (3): 277-288.

[27] Lambregts-Van Weezenbeek CS, Cobelens FG, Mensen EA, CommissievoorPraktische T. The Tuberculin Skin Test in the Netherlands: New Policies for an Old Test; Guideline from the Netherlands Tuberculosis Control Policy Committee. Ned TijdschrGeneeskd 2003; 147 (12): 543-546.

[28] Jahromi MK, Mood BS. Pulmonary Tuberculosis in Children.. Int J Infect 2014; 1 (3): e21116.

[29] Phongsamart W, Kitai I, Gardam M, Wang J, Khan K. A Population-Based Study of Tuberculosis in Children and Adolescents in Ontario. PIDJ 2009; 28 (5): 416-419.

[30] Comstock GW, Livesay VT, Woolpert SF. The Prognosis of a Positive Tuberculin Reaction in Childhood and Adolescence. Am J Epidemiol 1974; 99 (2): 131-138.

[31] Almeida LMD, Barbieri MA, Da Paixao AC, Cuevas LE. Use of Purified Protein Derivative to Assess the Risk of Infection in Children in Close Contact with Adults with Tuberculosis in a Population with High Calmette-Guerin-Bacillus Coverage. PIDJ 2001; 20 (11): 1061-1065.

[32] Connell TG, Ritz N, Paxton GA, Buttery JP, Curtis N. A Three-Way Comparison of Tuberculin Skin Testing, QuantiFERON-TB Gold and T-SPOT. TB in Children. PLoS ONE 2008; 3 (7): 1-7.

[33] Pai M, Riley LW, Colford JM. Interferon- Gamma Assays in the Immunodiagnosis of Tuberculosis: A Systematic Review. The Lancet Infectious Diseases 2004; 4 (12): 761-776. 
[34] Hill PC, Ota MO. Tuberculosis Case-Contact Research in Endemic Tropical Settings: Design, Conduct, and Relevance to Other Infectious Diseases. The Lancet Infectious Diseases 2010; 10 (10): 723-732.

[35] Marais BJ, Gie RP, SchaafHS, Hesseling AC, Obihara CC, Starke JJ, et al. The Clinical Epidemiology of Childhood Pulmonary Tuberculosis: A Critical Review of Literature from the Pre-Chemotherapy Era. Int J Tuberc Lung Dis 2004; 8 (3): 278-285.

[36] Marais BJ1, Gie RP, Schaaf HS, Hesseling AC, Obihara CC, Starke JJ, et al. The Natural History of Childhood Intrathoracic Tuberculosis: A Critical Review of Literature from the Pre-Chemotherapy Era. Int J Tuberc Lung Dis 2004; 8 (4): 392-402.

[37] Seddon JA, Delane S. Epidemiology and Disease Burden of Tuberculosis in Children: A Global Perspective. Infect Drug Resist 2014; 7: 153-165.

[38] Nelson LJ, Wells CD. Global Epidemiology of Childhood Tuberculosis. Int J Tuberc Lung Dis 2004; 8 (5): 636-647.

[39] Hsueh PR, Liu YC, So J, Liu CY, Yang PC, Luh KT. Mycobacterium Tuberculosis in Taiwan. J Infect 2006; 52 (2): $77-85$.

[40] Sandhu GK. Tuberculosis: Current Situation, Challenges and Overview of its Control Programs in India. J Glob Infect Dis 2011; 3 (2): 143-150.

[41] Zaman K. Tuberculosis: A Global Health Problem. J Health PopulNutr. 2010; 28 (2): 111-113.

[42] Sume G, Etogo D, Kabore S, Gnigninanjouena O, Epome S, Metchendje J. Seroprevalence of Human Immunodeficiency Virus Infection Among Tuberculosis Patients In The Nylon
District Hospital Tuberculosis Treatment Centre. EAMJ 2008; 85 (11): 529-536.

[43] Fanning A. Tuberculosis: Extra-pulmonary Disease. CMAJ 1999; 160: 1597- 1603.

[44] Haegi V. Extra-Pulmonary Tuberculosis Today. Schweiz Med Wonschenschr 1987; 117 (38): 1403-1408.

[45] Regie SS. Clinical Profile of Extra-Pulmonary Tuberculosis Cases Admitted and Diagnosed in a Tertiary Government Hospital from January 2006 to June 2010. PIDSP Journal 2013; 13 (2): 77-84.

[46] Islam SMS, Ahmed S, Amin MR, Begum V, Kabir ARML, Mollah MAH, et al, editors. National Guidelines for the Management of Tuberculosis in Children. 2nd ed. Bangladesh: WHO: 2016.

[47] Ullah S, Shah SH, Rehman AU, Kamal A, Begum N. Tuberculous Lymphadenitis in Afghan Refugees. J Ayub Med Coll Abbottabad 2002; 14 (2): 22-23.

[48] Van Loenhout-Rooyackers J, Laheij R, Richter C, Verbeek A. Shortening the Duration of Treatment for Cervical Tuberculous Lymphadenitis. ERJ 2000; 15 (1): 192.

[49] Hatwal D, Chaudhari S, Joshi AK, Tarhaur VK. Patterns of Extra-Pulmonary Tuberculosis in Children: A Hospital Based Study. IJCH 2013; 25 (1): 22-27.

[50] Napolean GS, Mercedes MP, Marte H, Hugo JO. Pulmonary Tuberculosis: Symptoms Diagnosis and Treatment. 19 Years Experience in a Third Level Pediatric Hospital. BMC Infect Dis 2014; 14 (1): 401.

[51] Gosai DK, Gosai JB, Shukla OS. Study of Clinical Profile of Childhood Extra-Pulmonary Tuberculosis. Int J Res Med Sci 2014; 2 (2): 501-505. 